\title{
Evidence for the involvement of descending pain-inhibitory mechanisms in the attenuation of cancer pain by carvacrol aided through a docking study
}

\author{
Adriana G. Guimarães ${ }^{\text {a }}$, Luciana Scotti ${ }^{b}$, Marcus Tullius Scotti ${ }^{b}$, Francisco J.B. Mendonça Júnior ${ }^{c}$, \\ Nayara S.R. Melo ${ }^{d}$, Rafael S. Alves ${ }^{d}$, Waldecy De Lucca Júnior ${ }^{e}$, Daniel P. Bezerra ${ }^{f}$, \\ Daniel P. Gelain ${ }^{\mathrm{g}}$, Lucindo J. Quintans Júnior ${ }^{\mathrm{d}, *}$ \\ a Department of Health Education, Federal University of Sergipe, Lagarto, SE, Brazil \\ ${ }^{\mathrm{b}}$ Federal University of Paraíba, João Pessoa, PB, Brazil \\ c State University of Paraiba, Biological Science Department, Laboratory of Synthesis and Drug Delivery, 58070-450 João Pessoa, PB, Brazil \\ ' Department of Physiology, Federal University of Sergipe, SãoCristóvão, SE, Brazil \\ e Department of Morphology, Federal University of Sergipe, SãoCristóvão, SE, Brazil \\ ${ }^{\mathrm{f}}$ Oswaldo Cruz Foundation, Laboratory of Tissue Engineering and Immunopharmacology, Salvador, BA, Brazil \\ ${ }^{g}$ Department of Biochemistry, Federal University of Rio Grande do Sul, Porto Alegre, RS, Brazil
}

\section{A R T I C L E I N F O}

Article history:

Received 3 June 2014

Accepted 28 August 2014

Available online 16 September 2014

Chemical compounds studied in this article:

Carvacrol (PubChem CID: 10364)

Morphine (PubChem CID: 5288826 )

Keywords:

Cancer pain

Hyperalgesia

Nociception

Monoterpene

Carvacrol

\begin{abstract}
A B S T R A C T
Aims: The present study evaluated the carvacrol (CARV) effect on hyperalgesia and nociception induced by sarcoma 180 (S180) in mice.

Main methods: Carvacrol treatment (12.5-50 mg/kg s.c.) once daily for 15 days was started $24 \mathrm{~h}$ after injection of the sarcoma cells in the hind paw (s.c.). Mice were evaluated for mechanical sensitivity (von Frey), spontaneous and palpation-induced nociception, limb use and tumor growth on alternate days. CARV effects on the central nervous system were evaluated through immunofluorescence for Fos protein. Molecular docking studies also were performed to evaluate intermolecular interactions of the carvacrol and muscimol, as ligands of interleukin-10 and $\mathrm{GABA}_{\mathrm{A}}$ receptors.

Key findings: CARV was able to significantly reduce mechanical hyperalgesia and spontaneous and palpationinduced nociception, improve use paw, decrease the number of positively marked neurons in lumbar spinal cord and activate periaqueductal gray, nucleus raphe magnus and locus coeruleus. CARV also caused significant decreased tumor growth. Docking studies showed favorable interaction overlay of the CARV with IL-10 and GABA Significance: Together, these results demonstrated that CARV may be an interesting option for the development of new analgesic drugs for the management of cancer pain.
\end{abstract}

@ 2014 Elsevier Inc. All rights reserved.

\section{Introduction}

Pain is one of the most common and distressing symptoms experienced by over half of all cancer patients (Schmidt et al., 2010) and its complex pathologic process is the main challenge for an effective treatment (Sarantopoulos, 2007). This symptom can interfere with daily activities of patients with neoplasms, reducing the quality of life and promoting important psychosocial disorders, in addition to an increase in the cost of treatment (Ling et al., 2012).

Throughout history, natural products and plant food supplements have contributed unequivocally to the pain and inflammation control

\footnotetext{
* Corresponding author at: Department of Phyisiology, Federal University of Sergipe Avenue Marechal Rondom, São Cristóvão, Sergipe, Brazil. Tel.: + 5579 21056645; fax: + 557932126640 .

E-mail addresses: lapec.ufs@gmail.com, lucindojr@gmail.com (L.J. Quintans Júnior).
}

(Di Lorenzo et al., 2013), the example of morphine isolated from Papaver somniferum and more recently, ziconotide, a peptide from snails which is used for the treatment of chronic pain. Hence, herbal medicines used in pain therapy can contribute to restoring the quality of life to a patient and may enhance conventional management of different types of pain, such as rheumatologic diseases, back pain, cancer, diabetic peripheral neuropathy and migraine (Zareba, 2009).

Carvacrol (CARV), a phenolic monoterpene found in Origanum oil (Lamiaceae family), has considerable analgesic and anti-inflammatory effects; it also modulates central neurotransmitter pathways, such as dopaminergic, serotoninergic and GABAergic systems, and the release of inflammatory mediators (Guimarães et al., 2010, 2012, 2013; Melo et al., 2010, 2011; Cavalcante Melo et al., 2012; Lima et al., 2013; Zotti et al., 2013). Although several studies describe its analgesic effects, there are no reports on the central nervous system (CNS) areas activated by CARV, as well as its potential use in cancer pain. 
Due to the emerging need for new therapeutic options for the treatment of cancer pain and the vast therapeutic potential of CARV, this study aimed to evaluate its effect on the nociception induced by Sarcoma 180 in mice and neuronal regions involved. We also performed a docking study between carvacrol and $\mathrm{GABA}_{\mathrm{A}}$, and IL-10 receptors, and a comparative docking between the carvacrol and the muscimol, a potent, selective agonist against the $\mathrm{GABA}_{\mathrm{A}}$ receptor.

\section{Materials and methods}

\section{Chemicals}

Carvacrol (5-isopropyl-2-methylphenol, CARV, 98\% purity), cremophor, sodium chloride, trypan blue, glycerol, DABCO, glycine and bovine serum albumin (BSA) were purchased from Sigma-Aldrich (St. Louis, Missouri, USA). Morphine and lactated Ringer's solution were purchased from Cristália (São Paulo, São Paulo, Brazil). Rabbit anti-Fos k-25 was obtained from Santa Cruz Biotechnology (Dallas, Texas, USA) and the donkey anti-rabbit Alexa Fluor 488 was purchased from Life Technologies (Carlsbad, California, USA).

\section{Animals}

Male Swiss mice used (28-32 g; 2-3 months of age) were randomly housed in appropriate cages at $21 \pm 2{ }^{\circ} \mathrm{C}$ on a $12 \mathrm{~h}$ light/dark cycle with free access to food (Purina ${ }^{\circledR}$, Brazil) and water. Experimental protocols were approved by the Animal Care and Use Committee (CEPA/UFS 43/ 09) at the Federal University of Sergipe, and all handling procedures were in accordance with the International Association for the Study of Pain (IASP) guidelines for the use of animals in pain research (Zimmermann, 1983).

\section{Tumor cell and implantation}

Sarcoma 180 (S180) tumor cells, which had been maintained in the peritoneal cavity of Swiss mice, were obtained from the Laboratory of Experimental Oncology at the Federal University of Ceará. A suspension of $10^{6}$ viable $\mathrm{S} 180$ cells per $25 \mu \mathrm{l}$ of lactated Ringer's solution was implanted subcutaneously into the plantar region of mice. Animals of the sham group received only $25 \mu \mathrm{l}$ of lactated Ringer's solution. This methodology was adapted from Kamioka et al. (1999) and Lee et al.(2009).

\section{Treatment and behavioral studies}

Twenty-four hours after administration of S180, animals ( $\mathrm{n}=10$ / group) were treated daily with vehicle (saline + cremophor $0.4 \% \mathrm{v} / \mathrm{v}$ ), CARV $(12.5,25$ or $50 \mathrm{mg} / \mathrm{kg}$ ) or morphine $(15 \mathrm{mg} / \mathrm{kg}$ ) by subcutaneous route, until the fifteenth day, and submitted to behavioral evaluation on alternate days. The investigator responsible for the behavioral evaluation was blind to the experimental situation of each animal.

\section{Mechanical hyperalgesia}

The animals were screened for the sensitivity towards mechanical stimulation generated by a gradual increase in pressure of a hand-held force transducer (electronic anesthesiometer, model: EFF-301, Insight ${ }^{\circledR}$, Brazil) adapted with a polypropylene tip. This stimulus evokes a hind paw flexion reflex that corresponds to the paw withdrawal followed by clear flinching movements.

\section{Spontaneous and palpation-induced nociception}

Mice were placed in boxes scattered and allowed to acclimate for $10 \mathrm{~min}$. Flinching behaviors were counted during a 10-min observation period. Afterwards, non-noxious palpation of the tumor-bearing paw was performed during $2 \mathrm{~min}$ and the number of flinching behaviors was quantified for $2 \mathrm{~min}$ (Sabino et al., 2003).

\section{Movement-evoked pain}

In the same boxes scattered, the limb use was assessed as previously described by Luger et al. (2001), through the observation of the mouse while walking in a continuous motion. Limping and/or guarding behavior of the right (sarcoma-treated) hind limb was rated on the following scale: $0=$ complete lack of use, $1=$ partial non-use, $2=$ limping and guarding, $3=$ limping, and $4=$ normal walking.

\section{Measurement of paw volume}

The effect of CARV on tumor growth caused by the plantar incubation of S180 was evaluated through right paw volume, which was measured by the dislocation of the water column of a plethysmometer (Insight ${ }^{\circledR}$, Brazil) before (time zero) and on every other day up to 15 days.

\section{Measurement of forelimb grip strength}

In order to check for possible changes in neuromuscular function, we measured the tension force of limbs using the commercial grip strength meter (Insight ${ }^{\circ}$, Brazil), before the treatment (s.c.) of tumor-free animals with vehicle or CARV $(12.5,25$ or $50 \mathrm{mg} / \mathrm{kg}$ ) and 30,60 and 120 min after treatment (Van Riezen and Boersma, 1969).

\section{Immunofluorescence}

Ninety minutes after the injection of CARV ( $50 \mathrm{mg} / \mathrm{kg}$; s.c.), morphine ( $15 \mathrm{mg} / \mathrm{kg}$; s.c.) or vehicle, the animals ( $\mathrm{n}=6$, per group) were perfused and the brains and lumbar spinal cords (L4-L6) were collected and cryoprotected for immunofluorescence processing to Fos protein.

Frozen serial transverse sections $(20 \mu \mathrm{m})$ of all brains and lumbar spinal cord lamina I were collected on gelatinized glass slides. The tissue sections were stored at $-80{ }^{\circ} \mathrm{C}$ until use. The sections were washed with phosphate buffer $(0.01 \mathrm{M})$ saline isotonic (PBS) 5 times for $5 \mathrm{~min}$. and incubated with $0.01 \mathrm{M}$ glycine in PBS for $10 \mathrm{~min}$. Nonspecific protein binding was blocked by the incubation of the sections for $30 \mathrm{~min}$. in a solution containing 2\% BSA. Then, the sections were incubated overnight with rabbit anti-Fos as primary antibodies (1:2000). Afterwards, the sections were incubated for $2 \mathrm{~h}$ with donkey anti-rabbit Alexa Fluor 594 as secondary antibodies (1:2000). The cover slip was mounted with glycerol solution ( $79 \%$ glycerol $+10 \%$ PBS $+1 \%$ DABCO). As an immunofluorescence control for non-specific labeling, sections were incubated without primary antibody. After each stage, slides were washed with PBS 5 times for 5 min. Pictures from Fos positive brain and spinal cord areas were acquired for each animal with an Axioskop 2 plus, Carl Zeiss, Germany. The brain regions were classified according to Paxinus and Watsu Atlas, 1997. Neurons were counted by the free software ImageJ (National Institutes of Health) using a plug-in (written by authors) that uses the same level of label intensity to select and count the Fos-positive cells.

\section{Docking studies}

The docking study investigated the intermolecular interactions of the carvacrol and muscimol, as ligands (Fig. 7) and 3 macromolecules available in the Protein Data Bank: crystal structure of human

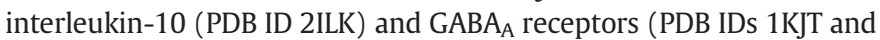
3D32). The simulations were performed on the Auto-Dock 4.2 software (Morris et al., 2009). Receptor and ligand preparation was carried out using VEGA ZZ 3.0.1 (Pedretti et al., 2004) and Molegro Molecular Viewer 2.5 .

Initially, the structures were saved in pqbqt format to be used for docking calculations. PyRx 0.8 software (Wolf, 2009) was used to aid the steps of job submission and analysis of the results. The grid maps were calculated with AutoGrid. The three-dimensional grid box with 60 Å grid size ( $\mathrm{x}, \mathrm{y}, \mathrm{z})$ with a spacing of $0.300 \AA$, was created. Each ligand was docked into this grid with the Lamarckian algorithm as implemented in AutoDock. The genetic-based algorithm ran 12 simulations per 


$$
\rightarrow-\text { Sham } \rightarrow-\operatorname{CARV}(12.5 \mathrm{mg} / \mathrm{kg}) \quad \rightarrow \text { CARV }(50 \mathrm{mg} / \mathrm{kg})
$$$$
\rightarrow-\text { Vehicle } \rightarrow \text { CARV }(25 \mathrm{mg} / \mathrm{kg}) \quad-\text { Morphine }(15 \mathrm{mg} / \mathrm{kg})
$$

\section{A.1}

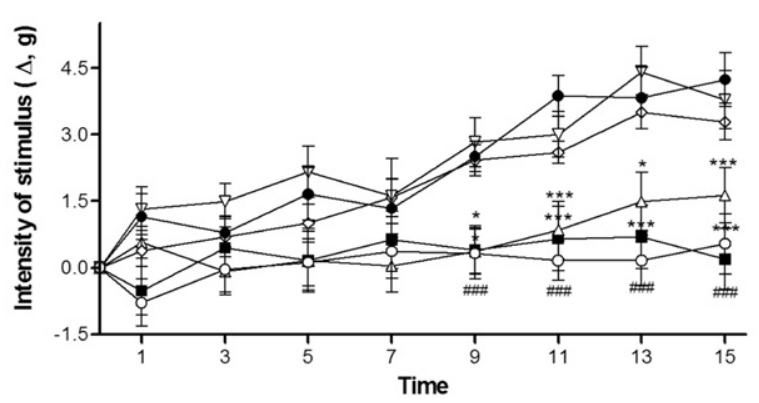

\section{B.1}

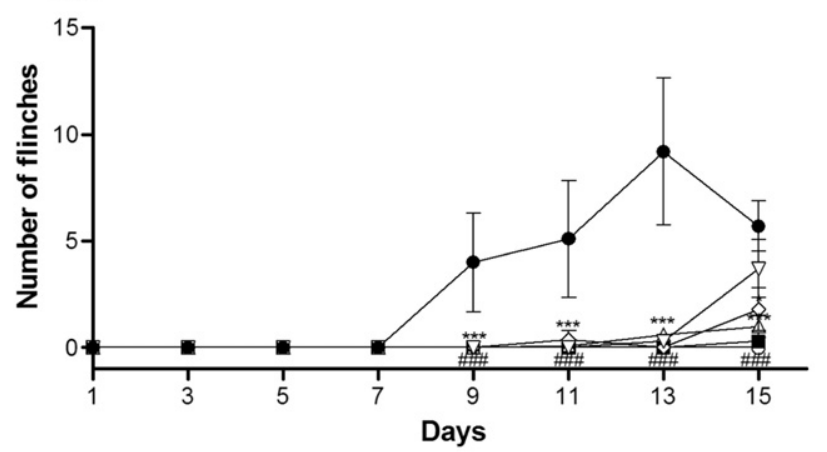

C.1

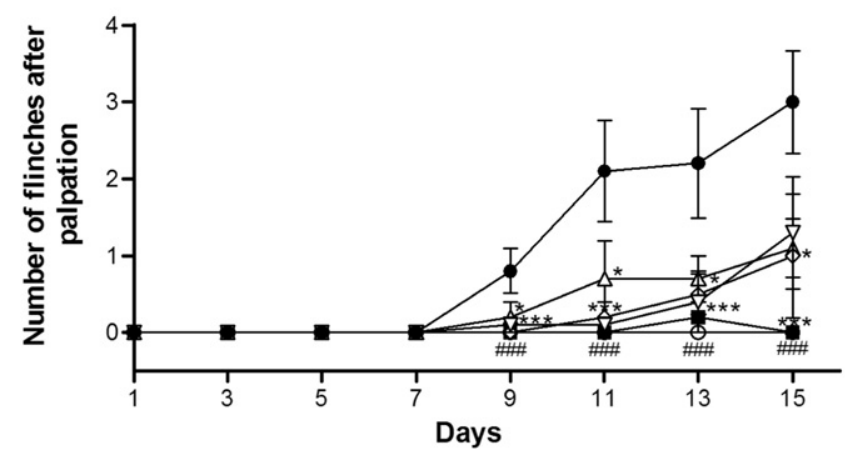

A.2

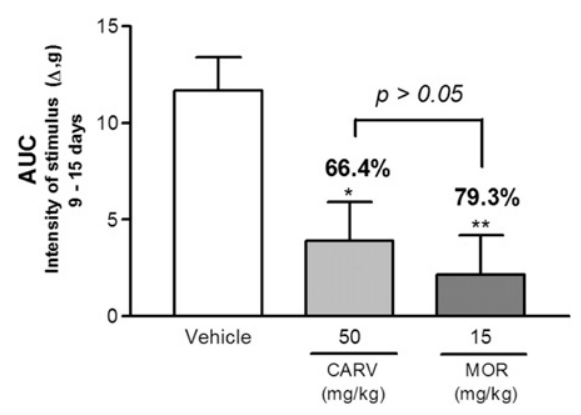

B.2

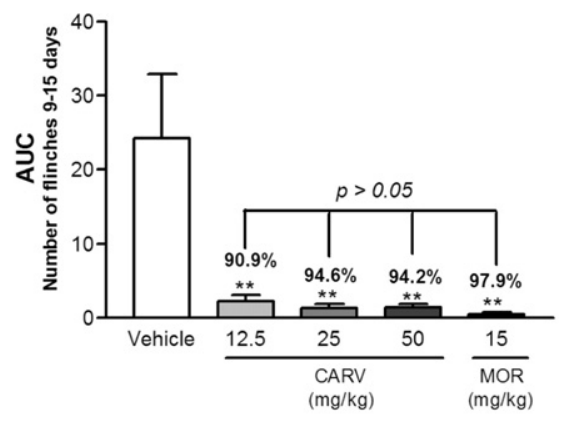

C.2

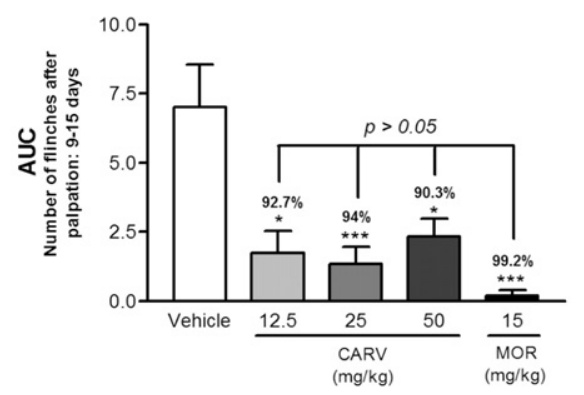

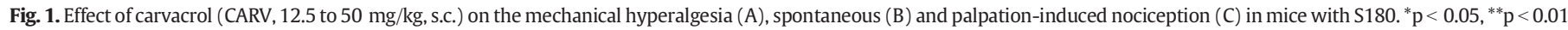
and ${ }^{* * *} \mathrm{p}<0.001$ vs. the control group, ${ }^{\# \# \#} \mathrm{p}<0.001$ vs. sham (ANOVA followed by Tukey's test).

substrate with 2,500,000 energy evaluations and a maximum number of generations of 54,000 . The crossover rate was increased to 0.8 , the rate of gene mutation was 0.02 and, the number of individuals in each population was 200. All other parameters were left at the AutoDock default settings. The results for each calculation were analyzed to obtain the affinity energy ( $\mathrm{kcal} / \mathrm{mol}$ ) values for each ligand conformation in its respective complex and the probable structure inaccuracies were ignored in the calculations. In order, the number of hydrogen bonds and noncovalent interactions between each ligand conformation and the residues of the macromolecules were observed using the Molegro Virtual Docker 6.0 (Motohashi et al., 2013) and the ligand maps were generated.

\section{Statistical analysis}

The data obtained were evaluated by means of one- and two-way analyses of variance (ANOVA) followed by Tukey's test. KruskalWallis followed by Dunn's test was applied to limb use. In all cases, differences were considered significant if $\mathrm{p}<0.05$, using the Graph Pad Prism (v 4.00) software (San Diego, CA, USA). The percent of inhibition was determined using the following formula: Inhibition\% $(\mathrm{PI})=100$. (control - experiment $) /$ control, with the data obtained by the area under the curve (AUC).

\section{Results}

In this study, $\mathrm{S} 180$ cells promoted a significant reduction $(\mathrm{p}<0.001)$ in the sensitivity threshold to mechanical stimulation on the control group (vehicle) when compared to tumor-free animals (sham group) which was maintained until the fifteenth day. After this period, paws of the animals started showing lesions, and then established the end point. Treatment of animals with CARV ( $50 \mathrm{mg} / \mathrm{kg}$; s.c.) was able to significantly reduce hyperalgesia, with an average inhibition percentage of $66.4 \%$. The treatment with morphine $(15 \mathrm{mg} / \mathrm{kg}$; s.c.) also promoted relief of hyperalgesic response with an average inhibition of $79.3 \%$ (Fig. 1.A). 

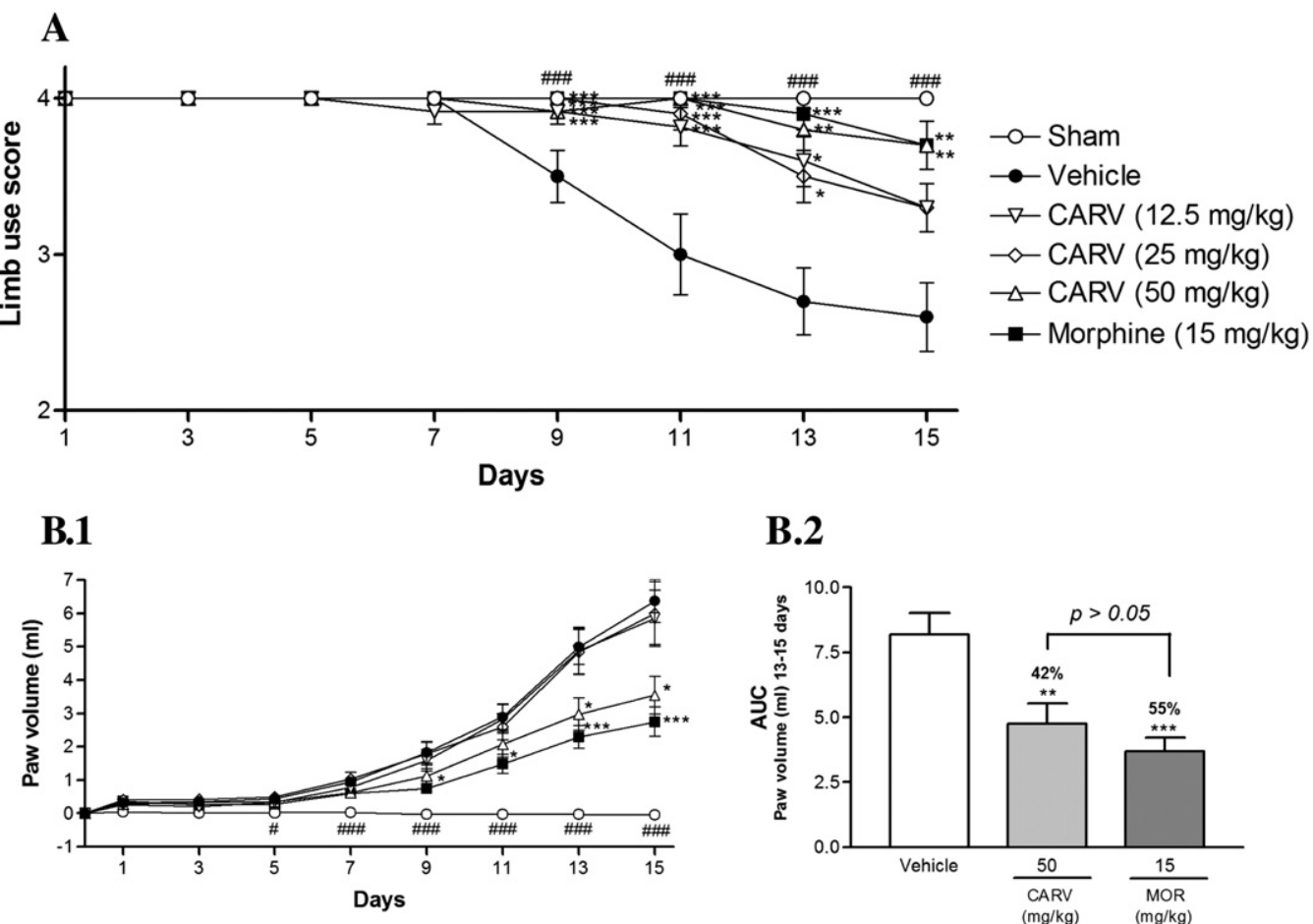

\section{B.2}

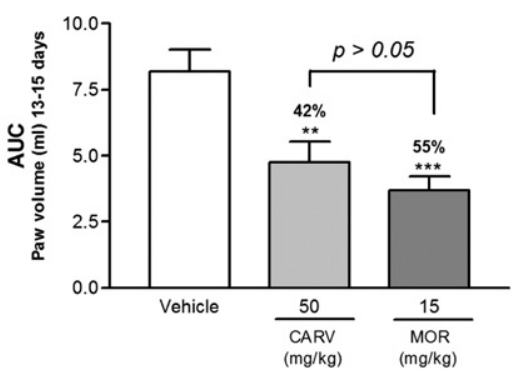

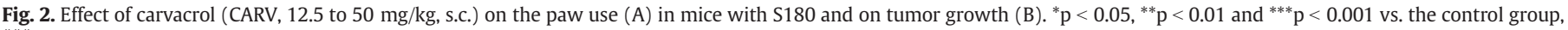
$\# \#$ p $<0.001$ vs. sham (ANOVA followed by Tukey's test for paw volume and Kruskal-Wallis followed by Dunn's test for limb use).

Mice of the control group also exhibited an increased number of spontaneous flinches as compared to the sham group $(\mathrm{p}<0.001)$, a reflection of ongoing cancer pain. CARV ( 12.5 and $25 \mathrm{mg} / \mathrm{kg}$ ) promoted a significant reduction $(\mathrm{p}<0.001)$ of this nociceptive response up to the 13th day, with average inhibition percentages of 90.9 and $94.6 \%$, respectively. CARV $(50 \mathrm{mg} / \mathrm{kg}$ ) and positive control were able to reduce the spontaneous nociception until the fifteenth day, presenting an inhibition of $94.2(\mathrm{p}<0.001$ until the 13th day and $\mathrm{p}<0.05$ on the 15th day) and $97.7 \%$ ( $p<0.001$ all days), respectively (Fig. 1.B).

Mice with sarcoma also exhibited a greater number of palpationevoked flinches as compared to shams $(\mathrm{p}<0.001)$. A reduction of flinches induced by non-nocive palpation was observed (Fig. 1.C) in mice treated with CARV at doses of 12.5 ( $\mathrm{p}<0.001$ up to the 13th day; PI $=92.7 \%$ ), 25 ( $p<0.001$ until the 11 th day and $\mathrm{p}<0.05$ on 13

\section{A}
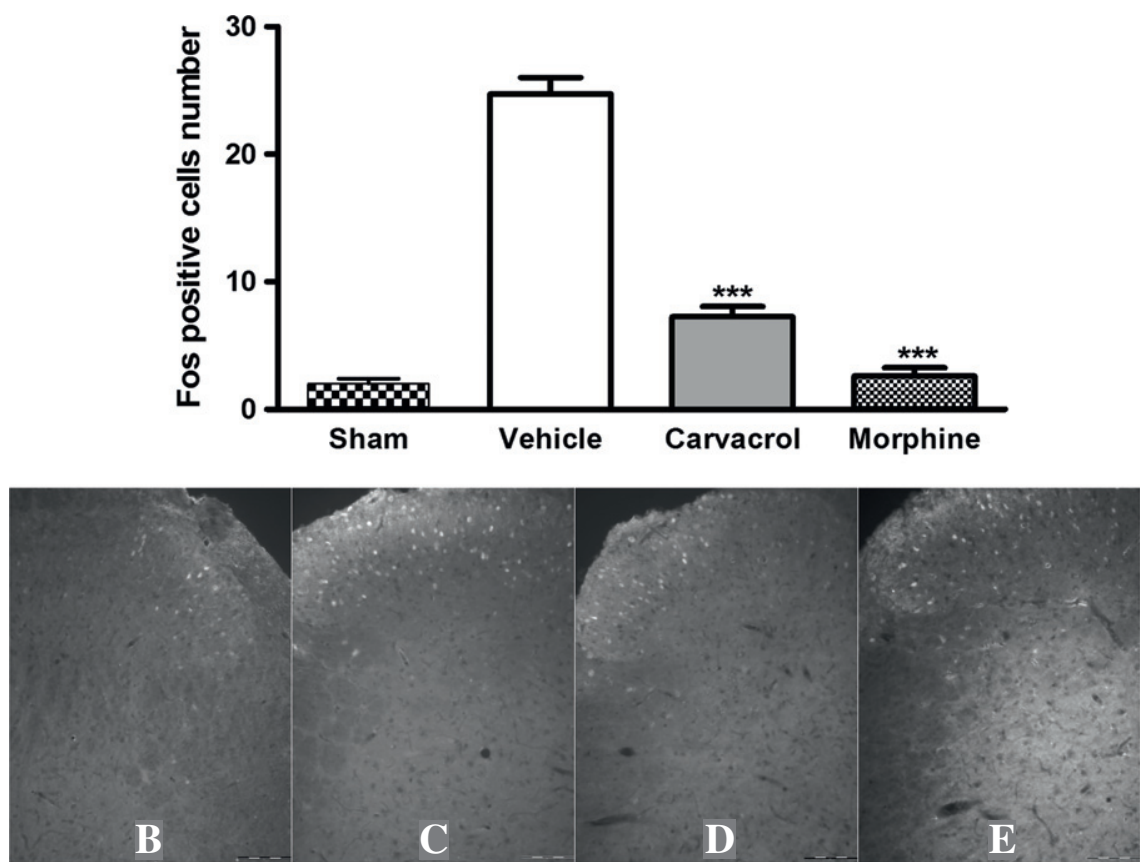

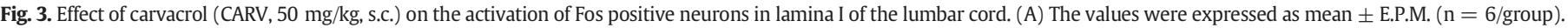

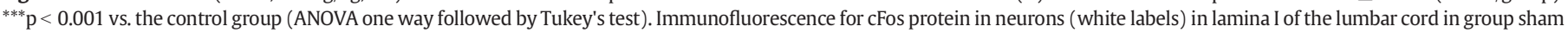
(B), vehicle (C), carvacrol (D) and morphine (E) (magnification: 20×; scale bars $20 \mu \mathrm{m}$ ). 


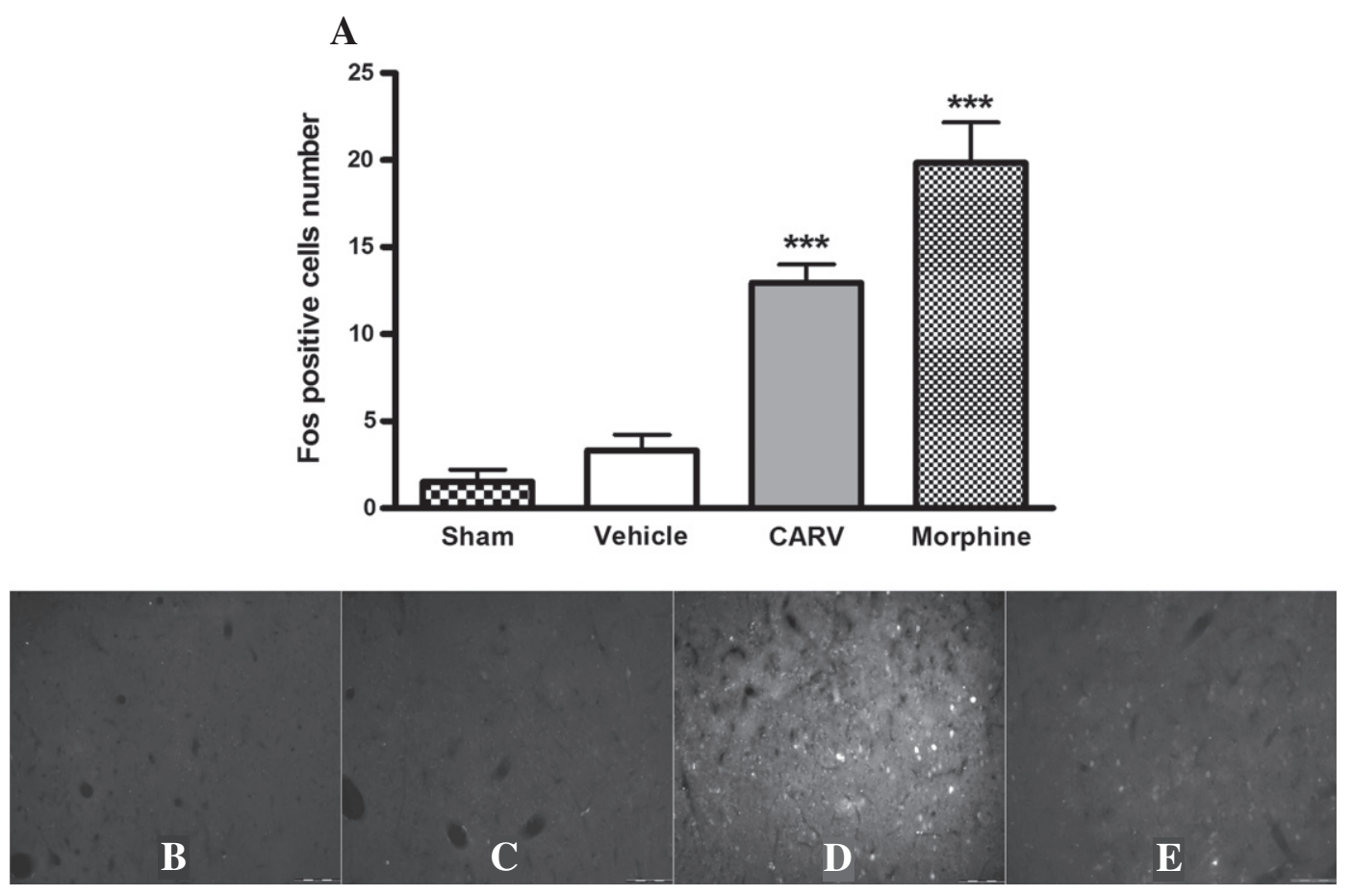

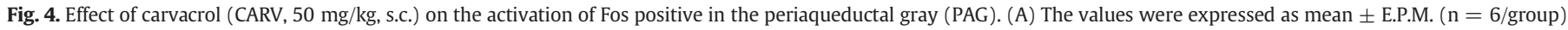

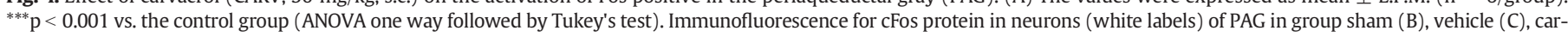
vacrol (D) and morphine (E) (magnification: 20×; scale bars $20 \mu \mathrm{m}$ ).

and 15 days $\mathrm{PI}=94 \%)$ and $50 \mathrm{mg} / \mathrm{kg}(\mathrm{p}<0.05 ; \mathrm{PI}=90.3 \%)$, and morphine $(\mathrm{p}<0.001 ; \mathrm{PI}=99.2 \%)$.

These mice also exhibited pain-induced impairment of their limbs as evidenced by a reduction in limb use during normal ambulation $(\mathrm{p}<0.001$ versus sham; Fig. 2.A). Ttreatment with CARV promoted an improvement in the limb use at doses of $12-25 \mathrm{mg} / \mathrm{kg}$ ( $\mathrm{p}<0.05$ up to the 11th day) and $50 \mathrm{mg} / \mathrm{kg}$ ( $\mathrm{p}<0.01$ and 0.05 until the 11th and 15th days, respectively), as observed by morphine ( $\mathrm{p}<0.01$ ).

The treatment effects of CARV and morphine on tumor development were assessed through the paw volume. CARV and morphine were able to reduce significantly paw volume with average inhibition percentages of 42.0 and $55.0 \%$, respectively (Fig. 2.B).
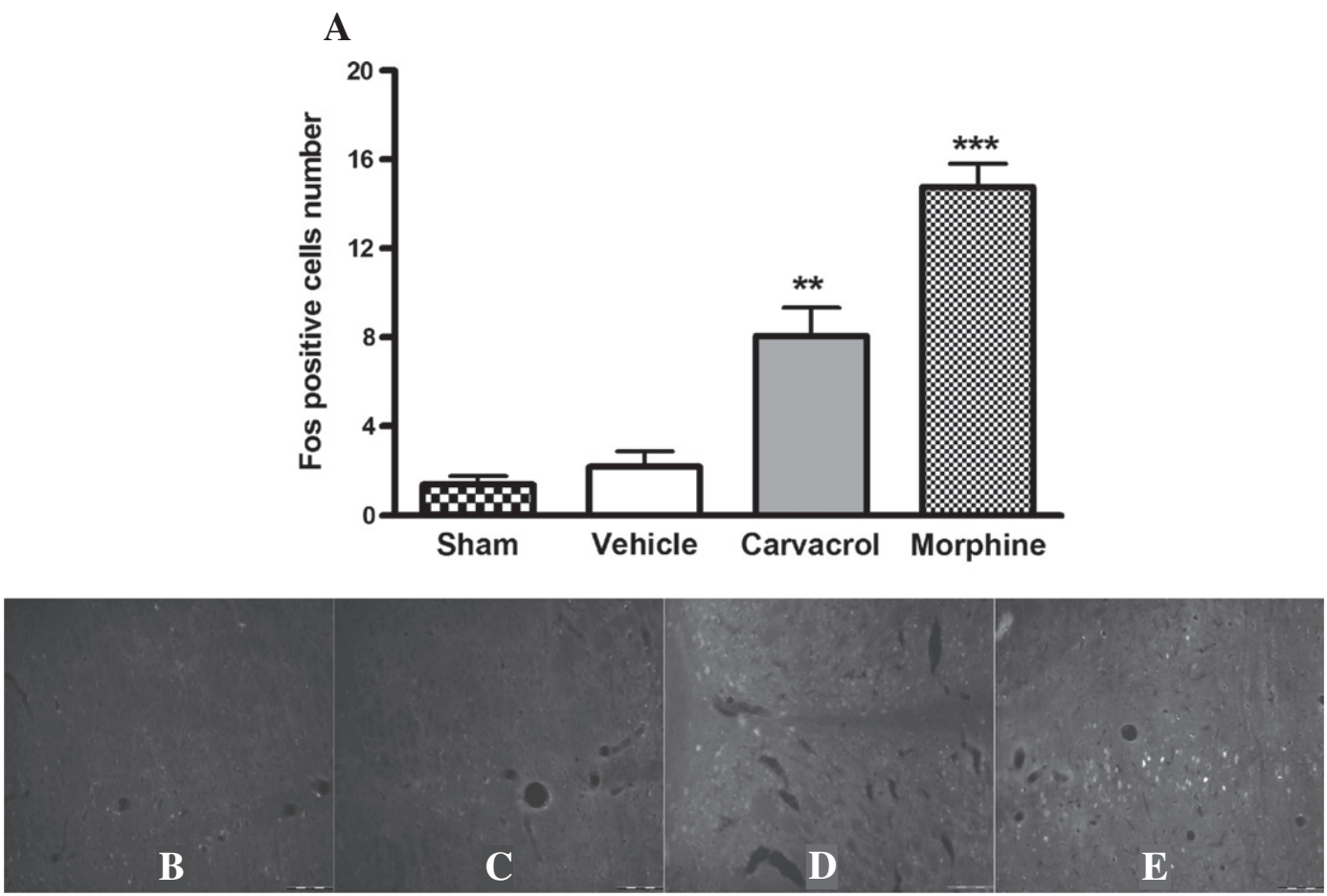

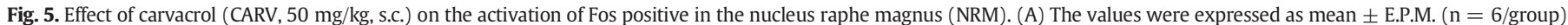

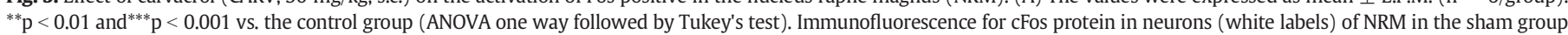
(B), vehicle (C), carvacrol (D) and morphine (E) (magnification: 20×; scale bars $20 \mu \mathrm{m}$ ). 


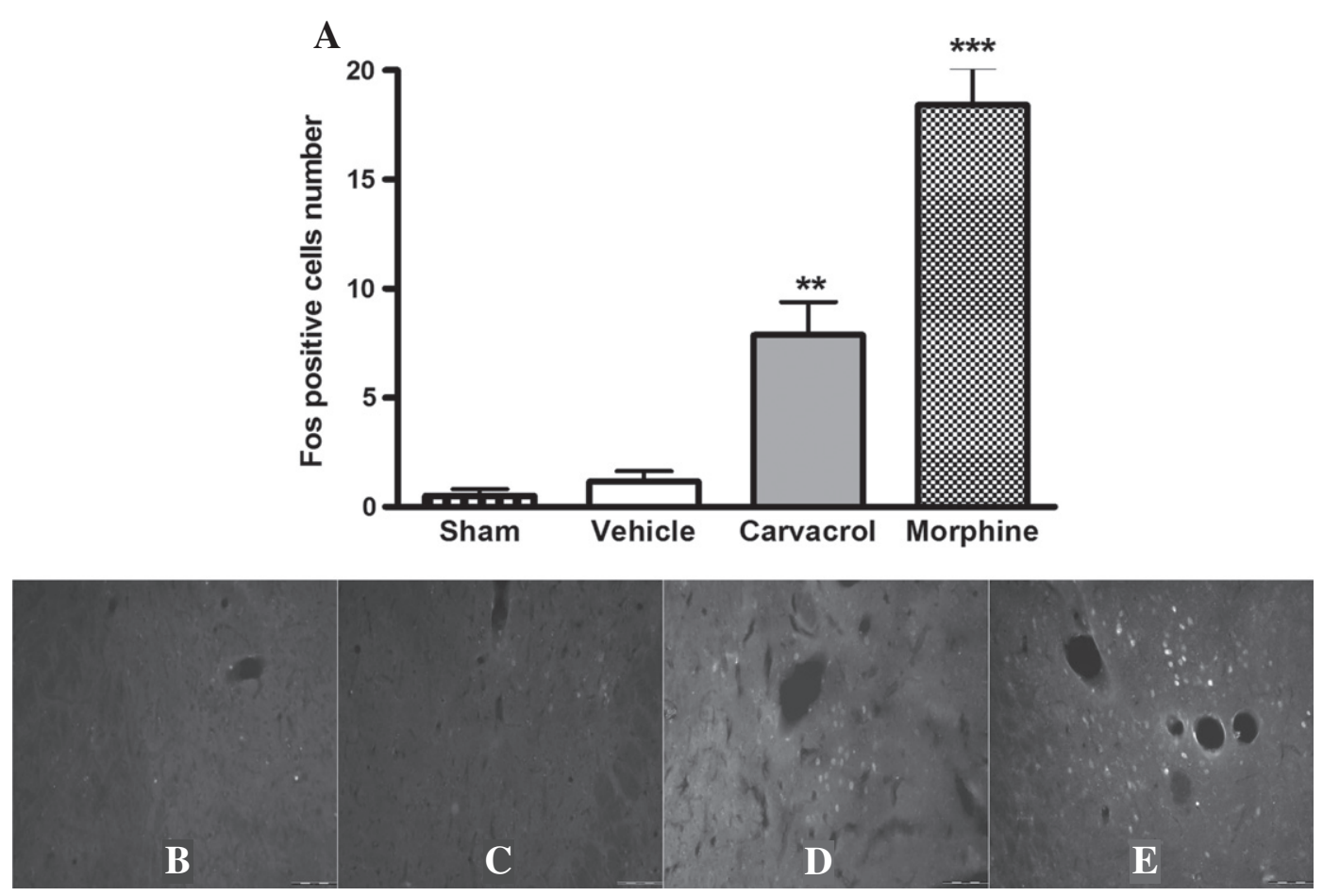

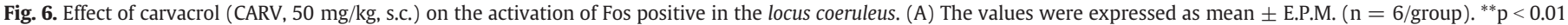

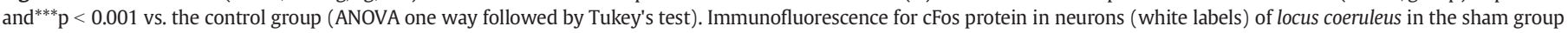
(B), vehicle (C), carvacrol (D) and morphine (E) (magnification: $20 \times$; scale bars $20 \mu \mathrm{m}$ ).

On the 15th day, animals with sarcoma showed a significant increase $(\mathrm{p}<0.001)$ in the number of positively marked neurons in the lamina 1 of the lumbar spinal cord (L4-L6), when compared to the sham group. This neuronal labeling was reduced $(\mathrm{p}<0.001)$ by the treatment with CARV (50 mg/kg) and morphine (Fig. 3), with an inhibition percentage of $70.8 \%$

Furthermore, animals treated with CARV $(50 \mathrm{mg} / \mathrm{kg}$ ) presented a significant increase in positively marked neurons in periaqueductal gray (PAG; p < 0.001; Fig. 4), nucleus raphe magnus (NRM) and locus coeruleus (LC) ( $p<0.01$; Figs. 5 and 6$)$, similar to morphine $(\mathrm{p}<0.001)$. The activation percentages in the PAG, NMR and LC, were, respectively, $74.4,93.6$ and $85.8 \%$.

Acute treatment of healthy animals with CARV at the doses tested was not able to change the grip strength of animals, ruling out the hypothesis of a myorelaxing activity of this compound (data not shown).

Table 1 shows the binding energies obtained in the formation of the ligand-macromolecule complexes and Fig. 8 reports the ligand maps calculated with the best conformations. When CARV is complexed with the IL-10, we find a negative energy value of $-3.30 \mathrm{kcal} / \mathrm{mol}$, indicating that the binding with the target is possible and favorable, also<smiles>Cc1ccc(C(C)C(=O)OCc2ccccc2)cc1O</smiles><smiles>NCc1cc(O)no1</smiles>

Muscimol

Fig. 7. Structures of the ligands used in docking studies.

indicating that the CARV is a better ligand than is the muscimol for $\mathrm{GABA}_{\mathrm{A}}$ receptor, as it can be seen in Fig. 8 .

\section{Discussion}

In this study, the S180 administration in the plantar region of mice was able to promote behavioral changes indicative of nociception through different methods of assessment such as mechanical hyperalgesia, spontaneous and palpation-induced nociception and movement-evoked nociception, which were attenuated by carvacrol.

Hyperalgesia indicates increased pain sensitivity and may include both a decrease in the threshold and an increase in the suprathreshold response of C and A- $\delta$ fibers (Sandkühler, 2009). Spontaneous nociception has been associated with the sensitization of C-fiber nociceptors in several nociception models (Uhelski et al., 2013). The palpation evoked nociception in animals with cancer mimics the allodynia, defined as pain in response to a non-nociceptive stimulus induced by low-threshold fibers, as A- $\beta$ fibers (Sandkühler, 2009). Both palpation-evoked pain and ambulatory behavior reflect what occurs from weight-bearing touching of affected limbs in advanced cancer patients (Sabino et al., 2003).

This sensitization of such fibers can be generated by immune-system cells such as polymorphonuclear cells (PMN) found in the peripheral regions of the $S 180$ (Sato et al., 2005), which secrete various factors that sensitize or directly excite, as prostaglandins, tumor necrosis factor- $\alpha$ (TNF- $\alpha$ ), endothelins, interleukin-1 (IL-1) and -6 (IL-6), among others (Mantyh et al., 2002). In this context, the effect of carvacrol on the mediator and cytokine release may have contributed to the control of pain (Wagner et al., 1986; Hotta et al., 2010; Guimarães et al., 2012; Jalali et al., 2013; Lima et al., 2013).

It was demonstrated that S180 promotes an increase in the number of positively marked neurons in the lamina 1 of the lumbar spinal cord, which was reduced by CARV. The expression of c-Fos in the superficial dorsal horn of the spinal cord has been used as a marker of activation of primary afferent terminals, and sensitization of terminals in 
Table 1

Binding energies of the complexes.

\begin{tabular}{|c|c|c|c|}
\hline & $\begin{array}{l}\text { Crystal structure of human interleukin-10 } \\
(\mathrm{kcal} / \mathrm{mol})(2 \mathrm{ILK})\end{array}$ & $\begin{array}{l}\text { Crystal structure of the GABA(A) } \\
(\mathrm{kcal} / \mathrm{mol})(1 \mathrm{KJT})\end{array}$ & $\begin{array}{l}\text { Crystal structure of the GABA(A) } \\
\text { (3D32) }(\mathrm{kcal} / \mathrm{mol})\end{array}$ \\
\hline Muscimol & - & -3.66 & -3.80 \\
\hline Carvacrol & -3.30 & -4.24 & -4.89 \\
\hline
\end{tabular}

inflammatory and sarcoma-induced bone cancer pain states (Mantyh et al., 2002).

Furthermore, CARV was able to increase a number of positively marked neurons in regions involved in descending inhibitory pain pathway such as PAG, NRM and LC. This pain control circuit can be modulated by different transmitters and specific receptor types and is an important site of action to pain-relieving drugs including opiates, cannabinoids, NSAIDs, and serotonin/norepinephrine reuptake blockers that mimic, in part, the actions of opiates (Ossipov et al., 2010).

We can see the binding energies of the ligand-receptor complexes through docking studies, in which negative energy values represent favorable interactions with the receptors. Our results showed that the interaction overlay of the CARV, how much each ligand atom contributes to the overall binding interaction with the targets $\mathrm{GABA}_{\mathrm{A}}$ is greater than muscimol, besides the favorable interaction with IL-10.

Melo et al. (2010) demonstrated that the CARV modulate GABAergic transmission, corroborating with the results observed in this study once there is a significant contribution of GABAergic neurons to the spinal projections that originate lateral to the NRM about pathway pain (Reichling and Basbaum, 1990). This monoterpene is also able to stimulate IL-10 expression (Lima et al., 2013), an anti-inflammatory cytokine that contributed to control neuropathic pain (Milligan et al., 2012). These central and peripheral effects may contribute to decreased stimulation of nociceptive pathways, facilitating pain control.

Moreover, the highest dose of CARV decreased the tumor growth, corroborating with other studies that showed its anti-tumor effect
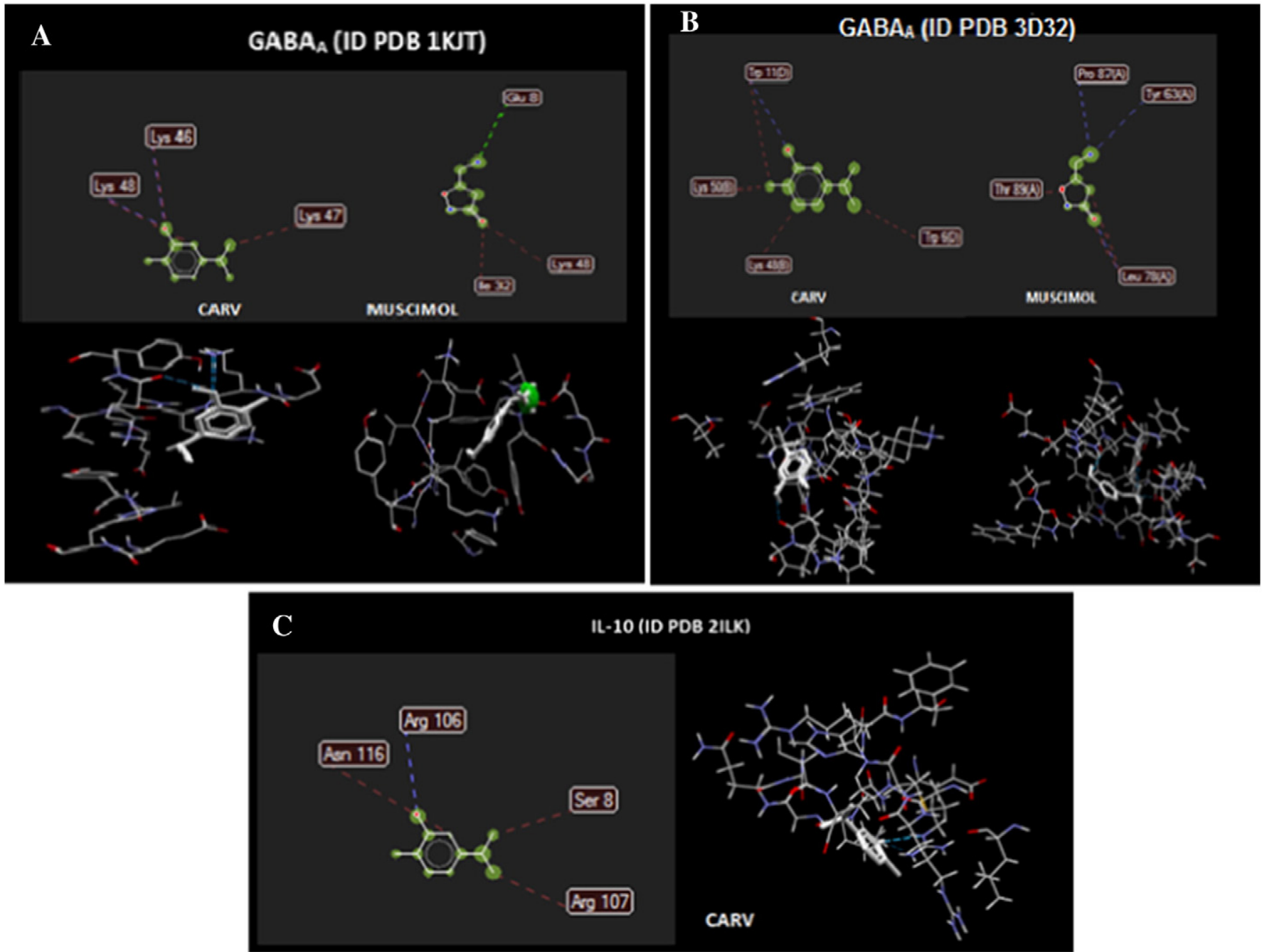

Fig. 8. Ligand maps. Blue lines-hydrogen bonds, red lines-steric interactions, green lines-eletrostatic interactions and green circles-interaction overlay. 
(Arunasree, 2010). Besides, its potent anti-inflammatory action may have contributed with this finding, once several studies have demonstrated that anti-inflammatory drugs are capable of reducing tumor initiation and/or progression of several cancers (Valle et al., 2013; Alfonso et al., 2014; Grabosch et al., 2014).

Finally, we demonstrated that CARV did not promote alterations in the intensity of grip strength, discarding the hypothesis of myorelaxing effect, corroborating with previously data published (Guimarães et al., 2010, 2012).

\section{Conclusions}

The big diversity of the action mechanisms of carvacrol makes it a candidate of interest for cancer pain treatment. Among them, stand out the neuromodulatory properties of the brain nuclei that comprise the descending pathway pain controls, such as PAG, NRM and LC, possibly because of their effect on the GABA receptors, which characterizes an important mechanism of analgesics with central action and is also of great relevance for the treatment of cancer pain.

\section{Conflict of interest statement}

The authors report no conflicts of interest. The authors alone are responsible for the content and writing of this paper.

\section{Acknowledgment}

We thank Mr. Osvaldo Andrade Santos for the technical support. This work was supported by grants from the National Council of Technological and Scientific Development (CNPq/Brazil) and the Research Supporting Foundation of State of Sergipe (FAPITEC-SE/Brazil). We also thank teacher Abilio Borghi for the grammar review of the manuscript.

\section{References}

Alfonso L, Ai G, Spitale RC, Bhat GJ. Molecular targets of aspirin and cancer prevention. $\mathrm{Br}$ J Cancer 2014;111(1):61-7.

Arunasree KM. Anti-proliferative effects of carvacrol on a human metastatic breast cance cell line, MDA-MB 231. Phytomedicine 2010:17(8-9):581-8.

Cavalcante Melo FH, Rios ERV, Rocha NFM, Citó M do C de O, Fernandes ML, de Sousa DP et al. Antinociceptive activity of carvacrol (5-isopropyl-2-methylphenol) in mice. J Pharm Pharmacol 2012;64(12):1722-9.

Di Lorenzo C, Dell'Agli M, Badea M, Dima L, Colombo E, Sangiovanni E, et al. Plant food supplements with anti-inflammatory properties: a systematic review (II). Crit Rev Food Sci Nutr 2013:53(5):507-16.

Grabosch SM, Shariff OM, Wulff JL, Helm CW. Non-steroidal anti-inflammatory agents to induce regression and prevent the progression of cervical intraepithelial neoplasia. Cochrane Database Syst Rev 2014;4. (CD004121).

Guimarães AG, Oliveira GF, Melo MS, Cavalcanti SCH, Antoniolli AR, Bonjardim LR, et al. Bioassay-guided evaluation of antioxidant and antinociceptive activities of carvacrol. Basic Clin Pharmacol Toxicol 2010;107(6):949-57.

Guimarães AG, Xavier MA de Santana MT, Camargo EA Santos CA, Brito FA et al Carvacrol attenuates mechanical hypernociception and inflammatory response. Naunyn Schmiedebergs Arch Pharmacol 2012;385(3):253-63.

Guimarães AG, Quintans JSS, Quintans Jr LJ. Monoterpenes with analgesic activity-a systematic review. Phytother Res 2013;27(1):1-15.

Hotta M, Nakata R, Katsukawa M, Hori K, Takahashi S, Inoue H. Carvacrol, a component of thyme oil, activates PPARalpha and gamma and suppresses COX-2 expression. J Lipid Res 2010;51(1):132-9.
Jalali S, Boskabady MH, Haeri-Rohani1 A, Eidi A. The effect of carvacrol on serum cytokines and endothelin levels of ovalbumin sensitized guinea-pigs. Iran J Basic Med Sci 2013;16(4):607-11.

Kamioka H, Osaka S, Suzuki K, Ryu J. Suppressive effects of bisphosphonate on bone resorption induced by murine sarcoma. Nihon Univ J Med 1999;41:121-33.

Lee H-J, Lee J-H, Lee E-O, Lee H-J, Kim K-H, Kim S-H, et al. Substance P and beta-endorphin mediate electro-acupuncture induced analgesia in mouse cancer pain model. J Exp Clin Cancer Res 2009;28:102.

Lima M da S, Quintans-Júnior LJ, de Santana WA, Martins Kaneto C, Pereira Soares MB, Villarreal CF. Anti-inflammatory effects of carvacrol: evidence for a key role of interleukin-10. Eur J Pharmacol 2013;699(1-3):112-7.

Ling C, Lui LYY, So WKW. Do educational interventions improve cancer patients' quality of life and reduce pain intensity? Quantitative systematic review. J Adv Nurs 2012; 68(3):511-20.

Luger NM, Honore P, Sabino MA, Schwei MJ, Rogers SD, Mach DB, et al. Osteoprotegerin diminishes advanced bone cancer pain. Cancer Res 2001;61(10):4038-47.

Mantyh PW, Clohisy DR, Koltzenburg M, Hunt SP. Molecular mechanisms of cancer pain. Nat Rev Cancer 2002;2(3):201-9.

Melo FHC, Venâncio ET, de Sousa DP, de França Fonteles MM, de Vasconcelos SMM, Viana GSB, et al. Anxiolytic-like effect of carvacrol (5-isopropyl-2-methylphenol) in mice: involvement with GABAergic transmission. Fundam Clin Pharmacol 2010;24(4):437-43.

Melo FHC, Moura BA, de Sousa DP, de Vasconcelos SMM, Macedo DS, et al. Antidepressantlike effect of carvacrol (5-isopropyl-2-methylphenol) in mice: involvement of dopaminergic system. Fundam Clin Pharmacol 2011;25(3):362-7.

Milligan ED, Penzkover KR, Soderquist RG, Mahoney MJ. Spinal interleukin-10 therapy to treat peripheral neuropathic pain. Neuromodulation Technol Neural Interface 2012; 15(6):520-6.

Morris GM, Huey R, Lindstrom W, Sanner MF, Belew RK, Goodsell DS, et al. AutoDock4 and AutoDockTools4: automated docking with selective receptor flexibility. J Comput Chem 2009;30(16):2785-91.

Motohashi Y, Igarashi M, Okamatsu M, Noshi T, Sakoda Y, Yamamoto N, et al. Antiviral activity of stachyflin on influenza A viruses of different hemagglutinin subtypes. Virol J 2013:10(1):118.

Ossipov MH, Dussor GO, Porreca F. Central modulation of pain. J Clin Invest 2010; 120(11):3779-87.

Pedretti A, Villa L, Vistoli G. VEGA-an open platform to develop chemo-bio-informatics applications, using plug-in architecture and script programming. J Comput Aided Mol Des 2004;18(3):167-73.

Reichling DB, Basbaum AI. Contribution of brainstem GABAergic circuitry to descending antinociceptive controls: I. GABA-immunoreactive projection neurons in the periaqueductal gray and nucleus raphe magnus. J Comp Neurol 1990;302(2):370-7.

Sabino MAC, Luger NM, Mach DB, Rogers SD, Schwei MJ, Mantyh PW. Different tumors in bone each give rise to a distinct pattern of skeletal destruction, bone cancer-related pain behaviors and neurochemical changes in the central nervous system. Int J Cancer 2003;104(5):550-8

Sandkühler J. Models and mechanisms of hyperalgesia and allodynia. Physiol Rev 2009; 89(2):707-58.

Sarantopoulos CD. Advances in the therapy of cancer pain: from novel experimental models to evidence-based treatments. Signa Vitae 2007;2(Suppl. 1):23-41. [1 de maio de].

Sato DYO, Wal R, de Oliveira CC, Cattaneo RII, Malvezzi M, Gabardo J, et al. Histopathological and immunophenotyping studies on normal and sarcoma 180-bearing mice treated with a complex homeopathic medication. Homeopathy 2005;94(1):26-32.

Schmidt BL, Hamamoto DT, Simone DA, Wilcox GL. Mechanism of cancer pain. Mol Interv 2010:10(3):164-78.

Uhelski ML, Cain DM, Harding-Rose C, Simone DA. The non-selective cannabinoid receptor agonist WIN 55212-2 attenuates responses of C-fiber nociceptors in a murine model of cancer pain. Neuroscience 2013;247:84-94.

Valle BL, D'Souza T, Becker KG, Wood III WH, Zhang Y, Wersto RP, et al. Non-steroidal anti-inflammatory drugs decrease E2F1 expression and inhibit cell growth in ovarian cancer cells. PLoS One 2013;8(4):e61836.

Van Riezen H, Boersma L. A new method for quantitative grip strength evaluation. Eur J Pharmacol 1969;6(3):353-6.

Wagner $\mathrm{H}$, Wierer M, Bauer R. In vitro inhibition of prostaglandin biosynthesis by essential oils and phenolic compounds. Planta Med 1986;3:184-7.

Wolf LK. New software and websites for the chemical enterprise. Chem Eng News Arch 2009;87(5):32

Zareba G. Phytotherapy for pain relief. Drugs Today 2009;45(6):445-67.

Zimmermann M. Ethical guidelines for investigations of experimental pain in conscious animals. Pain 1983;16(2):109-10.

Zotti M, Colaianna M, Morgese MG, Tucci P, Schiavone S, Avato P, et al. Carvacrol: from ancient flavoring to neuromodulatory agent. Molecules 2013;18(6):6161-72. 